\title{
Applying Wireless Sensor Networks to Solve Real-world Problems
}

\author{
Mohammad Hammoudeh \\ School of Computing, Mathematics and Digital Technology, Manchester Metropolitan University \\ M.Hammoudeh@mmu.ac.uk
}

\begin{abstract}
Wireless Sensor Networks (WSNs) is a mature research field that can be tracked back to the 1980, when the United States Defense Advanced Research Projects Agency (DARPA) started the Distributed Sensor Network (DSN) program to formally explore the challenges in implementing WSNs. Since then, WSNs progressed into academia and found home in civilian scientific research. Today, WSNs remains an active research topic with over 64,825 publications in IEEEXplore alone. Recent advances in semiconductor and networking technologies are driving the ubiquitous deployment of large-scale WSNs. These technologies enable a new generation of WSNs that differ greatly from networks studied as recently as 5 to 10 years ago. Today's stateof-the-art WSNs hardware platforms have lower costs and are expected to last longer opening the way into their deployment for any application. However, existing WSNs deployments are limited to experimental few hundred nodes networks. This talk explores the current challenges hindering the real-life deployment of large-scale WSN systems. The focus is to map historical WSNs deployment challenges and their severity against today's network and sensor hardware capabilities. Isolating factors that no longer have great effect on the deployment and maintenance costs of WSNs, is expected to instigate a wave of next generation WSNs deployment. To facilitate this aim, the talk will be focusing on WSN-based protocols/algorithms developed to solve current problems facing the deployment of large-scale WSNs. The talk draw on lessons learned from pilot deployments in different application areas including: space exploration, minerals mapping, heat diffusion, border security and flood prediction and control.
\end{abstract}

\section{Categories and Subject Descriptors}

C.2.1 [Network Architecture and Design]: Network Topology, C.2.2 [Computer-Communication Networks]: Network Protocols - Routing protocols.

C.2.3 [Computer-Communication Networks]: Network Operations - Network management.

\section{General Terms}

Protocols and Sensor Networks.

Permission to make digital or hard copies of all or part of this work for personal or classroom use is granted without fee provided that copies are not made or distributed for profit or commercial advantage and that copies bear this notice and the full citation on the first page. Copyrights for components of this work owned by others than ACM must be honored. Abstracting with credit is permitted. To copy otherwise, or republish, to post on servers or to redistribute to lists, requires prior specific permission and/or a fee. Request permissions from Permissions@acm.org.

IPAC '15, November 23-25, 2015, Batna, Algeria

(C) 2015 ACM. ISBN 978-1-4503-3458-7/15/11 ..\$15.00

DOI: http://dx.doi.org/10.1145/2816839.2816935

\section{Keywords}

Wireless Sensor Networks, WSN protocols, WSN technology.

\section{Short Biography}

Dr Mohammad Hammoudeh is a Senior Lecturer in Computer Networks and Security in the School of Computing, Math and Digital Technology at the Manchester Metropolitan University. He received his Ph.D. in Computer Science from the University of Wolverhampton in 2009, his MSc (Distinction) in Advanced Distributed Systems from the University of Leicester in 2007, his BSc (Hons) in Computer Communications from Hawaii University in 2004, and a DipCompSci in Computer Information Systems from Siblin Training College in 2002. His research interests are in highly decentralized algorithms, communication, and cross-layered solutions to wireless sensor networks. He also has research interests in pervasive and mobile computing, specifically in Internet of Things. He has been researching and publishing work that focuses on big sensory data mining and visualization. All his research projects are interdisciplinary, applied to real life problems. Latterly, his research focus is on the system design of distributed intelligent systems and their application within large-scale wireless sensor networks, including border security and monitoring, flood detection and control, as well as waste tracking and management. He is a highly proficient, experienced, and professionally certified cyber security professional, specializing in: Threat analysis; Information and network security management; Internet investigations; Penetration testing Cyber and insider investigations; Breach assessments and incident response; Forensic and crisis readiness planning; and Translation of technical concepts to non-specialists. He is the cofounder of the Future Networks and Distributed Systems. He is the general chair of the European Intelligence and Security Informatics Conference (EISIC) 2015. He has been an active member of the technical program committee on many international conferences and journals. Hammoudeh is regularly invited to talk at international conferences and workshops. 